\title{
El exilio de la cotidianidad ${ }^{1}$
}

\author{
Irene María ARTIGAS AlBARELLI \\ Universidad Nacional Autónoma de México
}

\begin{abstract}
En este ensayo se exploran algunas de las características de las naturalezas muertas relacionadas con el hecho de que se trata de textos que se ocupan de los objetos de nuestro entorno más cercano, esto es, de las cosas que normalmente pasamos por alto. A partir del análisis de un bodegón del pintor español Francisco de Zurbarán (1598-1664) y de una ecfrasis de Rafael Alberti (1902-1999), titulada justamente "Zurbarán" (1948), se presenta a la paradoja como uno de los recursos recurrentes en el género de la naturaleza muerta. Tanto en la paradoja como en la naturaleza muerta, la preocupación por la precisión y la exactitud, en la expresión y en el trazo, deriva en figuras de pensamiento más amplias que son lecciones que obligan a contemplar y especular.
\end{abstract}

PALABRAS CLAVE: naturalezas muertas, paradoja, Alberti, ecfrasis.

This essay explores some of the fundamental characteristics of still life, mainly those related to the fact that these works of art deal with the closest and most common things, those objects that we normally overlook. Analyzing a painting by the Spanish painter Francisco de Zurbarán (1598-1664) and an ekphrasis by the Spanish poet Rafael Alberti (1902-1999), entitled “Zurbarán” (1948), the paper discusses paradox as one of the recurrent figures of still life. In paradox and still life, the search for precision and exactness, both in expression and line, results in broader figures of thought that teach us how to see and to speculate.

KEY WORDS: still life, paradox, Alberti, ekphrasis.

La naturaleza muerta se ocupa de los objetos de nuestro entorno más cercano, de los platos de fruta, pan y queso; los vasos y jarrones con agua y flores, los libros y papeles de nuestras mesas; representa aquellas cosas que están a la mano y que consideramos

\footnotetext{
${ }^{1}$ Este trabajo se realizó con el apoyo de una beca de posdoctorado del Programa de Formación e Incorporación de Profesores de Carrera en Facultades y Escuelas para el Fortalecimiento de la Investigación (Profip), de la Dirección General de Asuntos del Personal Académico (DGAPA), en la Universidad Nacional Autónoma de México (UNAM). El texto se presentó en el encuentro De Metamorfosis y Otras Relaciones: Coloquio sobre Literatura y Artes, realizado el 7 y 11 de abril de 2008, en la Facultad de Filosofía y Letras de la UNAM.
} 
comunes y corrientes. Por eso es el género "menor" frente a aquellos que se centran en acontecimientos extraordinarios, dioses o personas importantes. Por eso también la naturaleza muerta como género de representación supone una contradicción de origen: ¿qué pasa cuando dirigimos nuestra atención a lo que normalmente pasamos por alto porque siempre está ahí, repitiéndose regular y continuamente?, ¿qué ocurre cuando representamos eso a lo que solemos no prestar atención?, ¿necesariamente se hace que lo cotidiano pierda su cotidianidad?, ¿cómo evitar esta contradicción que supone la participación en la realidad material sin evitar que la visión de lo cotidiano pierda su cualidad de no ser excepcional?, ¿ cómo habitar ese plano "menor" de realidad sin reafirmar los poderes y ambiciones del medio de representación? Estas cuestiones se desprenden de la contradicción esencial al género de la naturaleza muerta, contradicción que es el tema de este análisis de la ecfrasis “Zurbarán”, de Rafael Alberti, incluida en su libro A la pintura. Poema del color y la linea, ${ }^{2}$ publicado en 1948.

El término "naturaleza muerta" y sus equivalentes en francés, italiano y portugués se utilizaban comúnmente ya a principios del siglo XVIII para nombrar composiciones pictóricas de flores, frutas, vasos, platos, armas, libros, instrumentos musicales, curiosidades exóticas y cualquier otro tipo de objeto inanimado. El término que se usa en inglés y las lenguas germánicas es anterior y proviene del holandés stilleven, con el cual se intentaba diferenciar este tipo de pinturas de las que utilizaban modelos "leven" que se movían (Davenport, 1998: 3-4). Según Lajer-Burcharth (2005), la noción de muerte en la terminología del género data de 1756, cuando en Francia aquellos cuadros hasta entonces llamados nature reposé comenzaron a conocerse como nature morte. Este cambio hizo explícitos algunos de los temas y procesos semióticos característicos del género: a la contradicción mencionada arriba añadió específicamente el tema de la vanitas y el del ilusionismo visual. Muchos cuadros del género aluden al transcurso inexorable del tiempo, a la inutilidad de los bienes terrenales o la brevedad de la vida. Incluyen calaveras, relojes, flores secas, fruta podrida, insectos que devoran la comida, copas volcadas, velas apagadas que nos recuerdan la vanidad y finitud del mundo.

Rosalie L. Colie (1966) matiza el importante papel que juega el trompe l'oeil en la construcción de este tipo de cuadros, al considerar que es parte de un carácter paradójico más general. Colie se refiere a una de las obras de Sebastien Stoskopff (pintor francés que vivió de 1597 a 1657) y resalta el hecho de que en ella, junto a alimentos a medio consumir, se encuentra una canasta llena de copas de cristal.

\footnotetext{
${ }^{2}$ Francisco Onieva Ramírez (2006) considera este libro como un gran poema único: "es su mejor libro del destierro, uno de los más trabajados y mejor estructurados de toda su producción. Un libro en el que las palabras despliegan unas potencialidades no sólo significativas, sino también sensoriales, nunca antes logradas por el poeta gaditano" (290). Onieva describe su estructura de la siguiente manera: “Tras los poemas iniciales ‘1917' y ‘A la pintura', donde sintetiza motivos que después aparecerán, los poemas se dedican alternativamente a los grandes pintores, en orden cronológico, y a los elementos que intervienen en la ejecución de un cuadro o a la técnica pictórica (retina, mano, paleta, pintura mural, al lienzo, al pincel, a la línea, a la perspectiva, claroscuro, composición, al color, al ropaje, a la luz, a la sombra, momento, desnudo, gracia, acuarela y proporción)" (304). Para mayores detalles sobre el libro completo, véanse además: Herrera (2006), Fernández (2005), Guerrero (1999) y González (1990).
} 


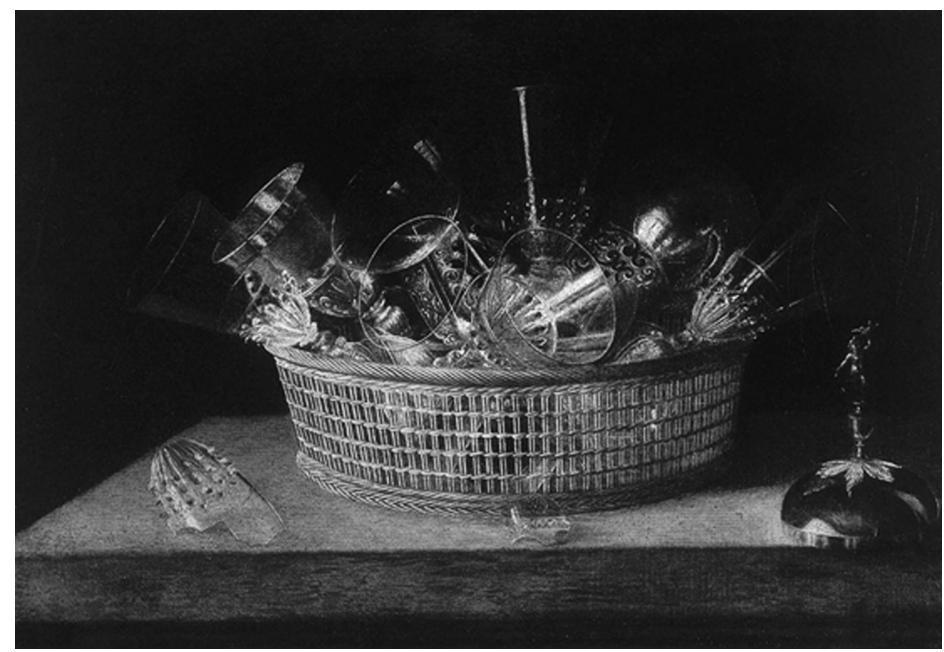

Sebastian Stoskopff, Naturaleza muerta con vasos en una canasta (1644), óleo sobre lienzo $(51$ x $62 \mathrm{~cm})$, col. pública.

La urdimbre del cesto es tan delicada, tan fina, que es posible ver los espacios vacíos en el entramado del tejido: los vasos son de un cristal tan delgado, tan transparente que permiten que la mirada los atraviese. Pareciera que se pinta el aire, lo pasajero, lo que no está ahí. Al observar este cuadro se nos invita a mirar "a través" del arte y a pensar que tal vez el tema de la pintura sea cierta verdad ontológica que reside más allá de la propia pintura (Colie, 1966: 274). Por eso, este autor compara el género de la naturaleza muerta con la paradoja y sostiene que, a pesar de su preocupación por la precisión y la exactitud tanto en el trazo como en la expresión, ambos géneros derivan, de detalles muy específicos, figuras de pensamiento más amplias que son lecciones que obligan a contemplar y especular. Contemplemos y especulemos, pues, con el poema de Alberti:

\section{Zurbarán}

Ni el humo, ni el vapor, ni la neblina.

Lejos de aquí ese aliento que destruye.

Una luz en los huesos determina

y con la sombra cómplice construye.

Pensativa sustancia la pintura, paraliza de luz la arquitectura.

Meditación del sueño, memorable visión real que en éxtasis domeña; severo cielo, tierra razonable de pan cortado, vino y estameña. 
El pincel, la paleta, todo es frente, medula todo pensativamente.

Piensa el tabique, piensa el pergamino del volumen que alumbra la madera; el pan se abstrae y se ensimisma el vino sobre el mantel que enclaustra la arpillera. $Y$ es el membrillo un pensamiento puro que concentra el frutero en claroscuro.

Ora el plato, y la jarra, de sencilla, humildemente persevera muda, y el orden que descansa en la vajilla se reposa en la luz que la desnuda. Todo el callado refectorio reza una oración que exalta la certeza.

La nube es un soporte, es una baja plataforma celeste suspendida, donde un arcángel albañil trabaja, roto el muro, en mostrar que hay otra vida. Mas lo que muestra es siempre un andamiaje para enganchar en pliegues el ropaje.

Rudo amante del lienzo, recia llama que blanquecinamente tabletea, telar del hilo de la flor en rama, pincel que teje, aguja que tornea. Nunca la línea revistió más peso ni el alma paño vivo en carne y hueso.

Fe que da el barro, mística terrena que el color de la arcilla sube al cielo, mano real que al ser humano ordena mirarse ante el divino, paralelo. La gloria abierta, el monje se extasía al ver volar la misma alfarería.

Pintor de Extremadura, en ti se extrema, dura y fatal, la lidia por la forma. El pan que cuece tu obrador se quema en el frío troquel que lo conforma. Gire en tu eternidad la disciplina de una circunferencia cristalina.

Las ocho estrofas del poema constituyen meditaciones individuales sobre un aspecto o un tema de los cuadros de Zurbarán (1598-1664), aunque varias de las ideas se 
repitan en varias estrofas: en unas se habla de una de las pinturas, mientras que otras son observaciones que podrían aplicarse a diversos cuadros. Pensemos, entonces, que el poema completo funciona conformando un modelo pictórico complejo (Yacobi, 1998), que presenta una configuración descriptiva que remite a varios cuadros de Zurbarán y, además, figuras de contradicción que se desprenden del género de la naturaleza muerta. A partir del reconocimiento de la alusión y descripción de varios cuadros específicos de Zurbarán y al efecto de ellos en conjunto, veremos cómo el poema opone los planos cotidiano/sagrado y nos obliga a ver cada pintura y cada tema siempre frente a su opuesto.

En la primera estrofa se enfatiza la claridad de los cuadros, que, cómplices de la oscuridad, apartan la neblina que se interpone entre nosotros y las cosas. Así, la obra de Zurbarán queda descrita desde el principio del poema como una acción del pensamiento que utiliza la luz y la sombra para disipar cualquier cosa que emborrone la visión. La segunda estrofa, en sus primeros cuatro versos, se refiere a cuadros como La visión de san Pedro Nolasco, en la que se representa al santo dormido y su sueño, y el Milagro de san Hugo en el refectorio, ${ }^{3}$ con un grupo de monjes sentados a la mesa.

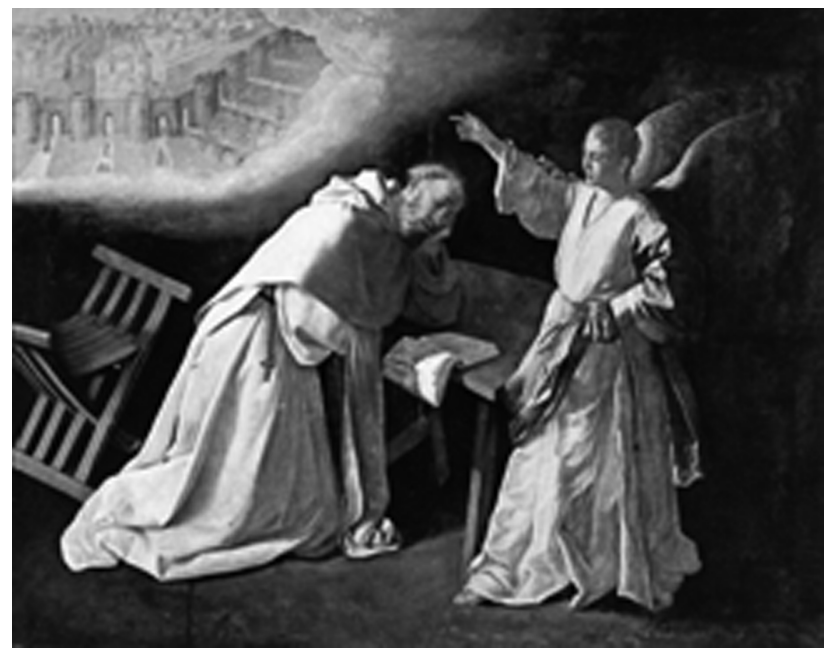

La visión de san Pedro Nolasco (1629), óleo sobre lienzo (170 x 223 cm), Museo del Prado.

${ }^{3}$ La escena del cuadro se refiere a un milagro acontecido a san Bruno, quien, junto con los seis primeros monjes de la Orden, comía gracias a lo que les daba el obispo de Grenoble, san Hugo. Un domingo les mandó carne, y los monjes se preguntaron si sería conveniente comerla o no. Mientras hablaban un profundo sueño los inundó, sueño que se prolongaría durante toda la cuaresma. San Hugo estaba de viaje y cuando volvió el miércoles santo fue a visitar a los cartujos. Cuando llegó los monjes despertaron sin tener conciencia del tiempo que había pasado. Entonces, la carne que estaba en los platos se convirtió en cenizas, lo cual se interpretó como un mensaje divino que aprobaba la abstinencia de los monjes. 


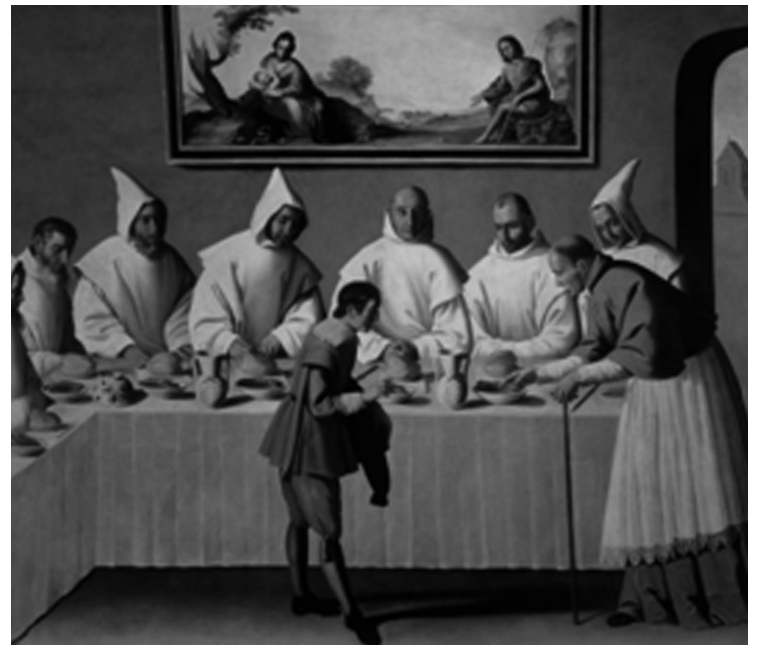

Milagro de san Hugo en el refectorio (1629),

óleo sobre lienzo, Museo Provincial de Bellas Artes de Sevilla.

ttp:www.spanisharts.com/history/barroco/imágenes/zurbaran/sanhugo.html

El pareado final regresa a la idea de pensamiento que se expresaba en el pareado de la primera estrofa. Esta noción se retoma en la tercera estrofa como tema central, pero en ella también hay referencia a objetos de diversas pinturas (los primeros dos versos a La Anunciación, los segundos dos a El milagro de san Hugo en el refectorio y el pareado a Naturaleza muerta con membrillo); los objetos tienen tal sustancialidad que se les otorga conciencia.

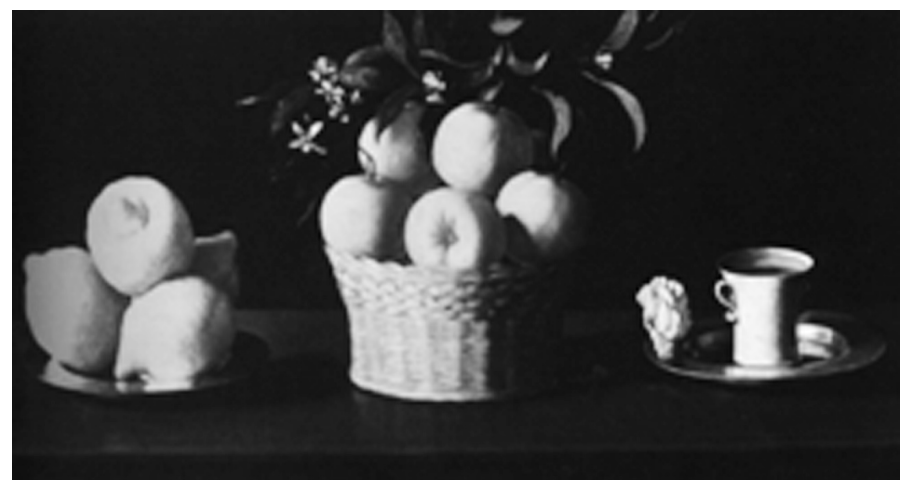

Plato con limones, cesta con naranjas y taza con una rosa (1633), $(60 \times 107 \mathrm{~cm})$, Norton Simon Fundation, Los Ángeles. 


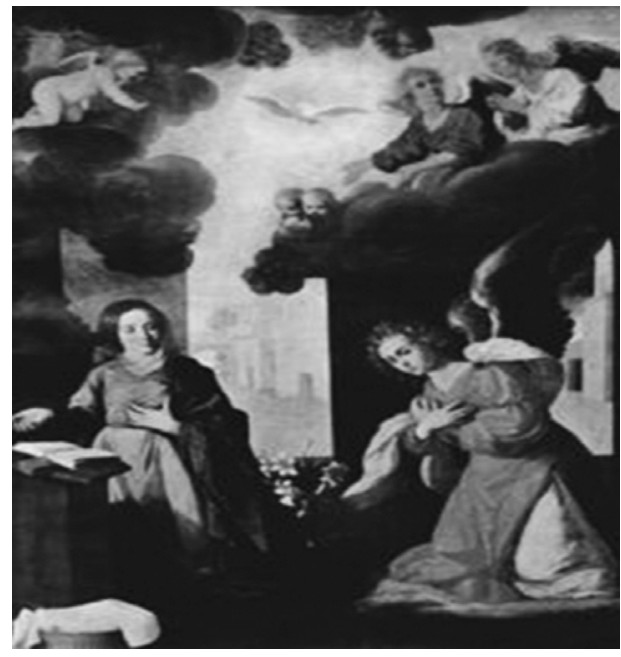

La Anunciación (1638), (161 x $175 \mathrm{~cm})$, Museo de Pintura. Grenoble.

De esta forma se nos anuncia la siguiente estrofa, la cuarta, a la cual prestaremos más nuestra atención y que se centra en el bodegón del Museo del Prado. Carolyn L. Tipton la describe de la siguiente manera: "Esta estrofa continúa desarrollando la noción de los objetos como sujetos de conocimiento y les atribuye piedad; así pretende dar cuenta del fuerte sentido de espiritualidad que la pintura da a quien la observa"4 (1997: 215). Para ella y para Alberti los objetos poseen una gran carga espiritual y piadosa, no por nada en el poema oran, meditan, piensan.

Recordemos que la pintura de Zurbarán se produce en un régimen visual en el cual la imagen puede ser una forma de acercarse a lo divino. Como menciona Bryson (1990), en los Ejercicios espirituales (1522) de san Ignacio, por ejemplo, se pretende construir imágenes que consigan enfocar la subjetividad completamente y apartarla de la acedia o pereza mental. Así, se sugiere a los fieles que, en una escena de la Crucifixión, apliquen el sentido del oído para escuchar el discurso de cada uno de los participantes, las blasfemias de los soldados, las palabras del ladrón que insulta a Jesucristo, las del que lo reconoce como el Señor o las palabras que la Virgen no dice; que también hagan funcionar el sentido del gusto y noten la amargura del corazón de María al ver a su hijo crucificado, y la del corazón de Jesús que sufre sus penas y las de la Virgen; que huelan el perfume de las virtudes de Jesús al morir, y que sientan sus heridas cuando internamente besen la cruz. La formación de imágenes es el vínculo entre la intensidad espiritual y el texto bíblico; según Bryson, los Ejercicios espirituales no sólo deben leerse, sino

\footnotetext{
4 "This stanza, continuing the notion of cognizant objects, attributes piety to the tableware, thinking thus to account for the strong sense of spirituality this painting gives its viewer."
} 
vivirse. Los objetos de los cuadros de Zurbarán se nos presentan, entonces, como esas imágenes que vinculan la realidad más cotidiana con la realidad espiritual.

Veamos con más detalle el Bodegón del Museo del Prado: cada vasija registra y dramatiza la historia de su manufactura. Los cacharros de barro parecen remitirnos al torno del ceramista y a las manos que moldearon la arcilla: el primer cántaro, a la derecha, exhibe el trabajo de alguna herramienta que la marcó cuando aún estaba fresca; el alargado cuello de la siguiente pieza sólo pudo deberse a la maestría de quien realizó las franjas que lo adornan; el canto de la siguiente vasija también muestra la huella de las manos que lo tornearon y el último cacharro nos remite al trabajo en metal que incluye el grabado, el cincelado y el pulido (Bryson,1990: 71).

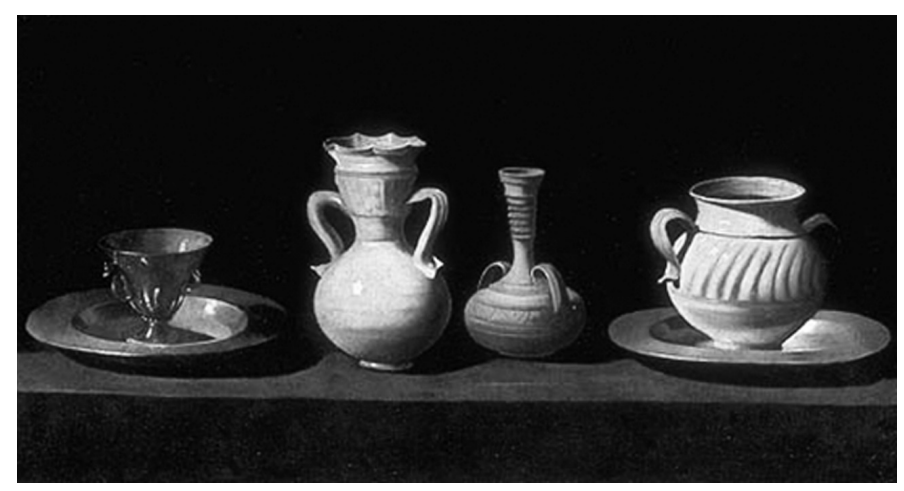

Francisco Zurbarán, Bodegón (46 x 84 cm), Museo del Prado.

Esta naturaleza muerta hace referencia a las manos que construyeron los objetos y a las manos que los utilizarán. El espacio entre los cacharros y el oscuro fondo del cuadro se opone a la idea del punto de fuga que la perspectiva albertina utilizaba para hacer del cuadro una ventana. Por eso, Stoichita (1993) explica que los antecedentes de las naturalezas muertas no están en la representación de ventanas, sino en la de nichos. Bryson (1990) comenta que el bodegón del cuadro de Zurbarán no es muy profundo y presenta claves contradictorias. La referencia a las manos que formaron los cacharros contradice la referencia al ojo, que se enfrenta a zonas oscuras yuxtapuestas a otras muy brillantes: un espacio que parecería coherente táctilmente hablando, se ilumina de manera dramática; así, el claroscuro construye una línea que divide la oscuridad de la claridad y que crea formas dirigidas al ojo que no corresponden a nada conocido por el tacto. El claroscuro obliga a prestar más atención, a realmente ver la escena. La pintura exige que nuestra percepción se olvide de las repeticiones y la rutina a las que estamos acostumbrados al habitar el mundo: la intromisión tan fuerte de la luz en la alacena es dolorosa y el ojo tiene que actuar; "rutas ópticas en desuso tienen que volver a abrirse y funcionar", nos dice Bryson (76). Así, la visión se eleva del mundo caído. 
Las naturalezas muertas de este pintor español otorgan la habilidad de ver lo insignificante con una visión más clara (gracias al hiperrealismo o al claroscuro añadido a la representación de la textura de los objetos); son cuadros que se presentan como dones espirituales que pintan lo invisible. Ahora bien, esto no quiere decir que se dejen llevar por la imaginación: siempre regresan a lo que es familiar en busca de la sobriedad y el autocontrol exigidos; intentan alejarse de la ilusión para recordar que la visión tiene un lugar y poderes específicos. Al hacernos conscientes de las cosas que normalmente dejamos de ver porque son muy comunes, al volverlas visibles, el campo visual parece perder toda familiaridad. Así, "el extrañamiento confiere a estos objetos una especie de coseidad dramática; la intensidad de la percepción produce un exceso tal de brillo y foco que la imagen parecería no ser de este mundo"5 (Bryson, 1990: 87).

De ahí el efecto de este tipo de pinturas y que varios críticos, al ver las naturalezas muertas de Zurbarán, piensen en la frase de santa Teresa: "Entended que, si es en la cocina, entre los pucheros anda el Señor, ayudándonos en lo interior y lo exterior" (Tipton, 1997; Stoichita, 1993). Son obras en las que las cosas están cargadas de lo más cotidiano y lo más sagrado al mismo tiempo.

En el poema de Alberti, la paradoja a la que nos hemos estado refiriendo con respecto al poder de este bodegón de transfigurar lo más trivial es explícita: "Todo el callado refectorio reza una oración que exalta la certeza". Y lo hace, recordemos, a través de lo que se presenta como una serie de figuras más; entre otras, apuntaremos la personificación ("ora el plato", "la jarra persevera, muda"); la antítesis ("el pan se quema en el frío troquel"), y el oxímoron ("la mística terrena"). Los objetos oran en silencio, son mudos que rezan e iluminan la oscuridad de la despensa. Anteriormente decíamos que el ojo que veía estos cuadros "sufría" al intentar explicar la luz en los objetos y la oscuridad del plano en el que se encuentran. Estas rutas ópticas tan inusuales, según Bryson, intentaban hacer que los objetos más comunes se inundaran de fascinación y fuerza inesperadas. Lo mismo podemos decir del poema completo. Parecería ser sencillo: ocho sextetos endecasílabos con rima ababcc (sexta rima). Según Tipton, su forma se ajusta a su tema: no fluye, en cada estrofa hay puntos que separan los cuatro primeros versos del pareado final; cada sexteto se separa de los otros, está cerrado, autocontenido; como los objetos de los cuadros de Zurbarán, que están perfectamente definidos, con contornos precisos y finos.

Difiero de Tipton en este punto porque las repeticiones y el uso de palabras y figuras que se relacionan siempre con la contradicción crean en el poema relaciones entre todas y cada una de las estrofas: el poema se presenta así como un intrincado tejido. A la antítesis y el oxímoron tendríamos que añadir el contraste y la repetición constantes debidos al uso de opuestos (luz/oscuridad, cielo/tierra, alma/carne y hueso, fatal/eternidad) y de sinónimos o palabras derivadas de la misma raíz (pensamiento, meditación,

\footnotetext{
5 “(de)familiarisation confers on these things a dramatic objecthood, but the intensity of the perception at work makes for such an excess of brilliance and focus that the image and its objects seem not-quite of this world".
} 
ensimismamiento, abstracción; orar, rezar, oración; sencilla, humildemente; muda, callado; soporte, plataforma, andamiaje; nube, celeste, otra vida; barro, arcilla).

Pero la complejidad tampoco se queda ahí. El tema de la mística de los objetos se refuerza por el modelo pictórico al que el poema se refiere: Zurbarán, pintor de santos y pintor de despensas; la naturaleza muerta como el género de la paradoja constante, como el género en el cual la techné se convierte en el verdadero tema. En este caso, Alberti llega al extremo de repetir la misma palabra en la última estrofa: "Extremadura"/“extrema y dura”, y hace evidente que, si Zurbarán buscaba la iluminación en oscuras despensas, él está intentando dar forma al mundo, un mundo golpeado por la guerra y el exilio.

Recordemos que en 1939 Alberti había tenido que abandonar España debido a la derrota de las fuerzas republicanas. Viviría un exilio de casi cuarenta años, en Argentina, Francia e Italia, y su obra enfatizaría aún más un tema que ya le era recurrente: el retorno a tiempos mejores y lugares queridos. En A la pintura, específicamente, intenta reconformar el país y el tiempo perdidos. El poema que nos ocupa y el libro del cual forma parte son la manifestación de un deseo del orden, la belleza y la armonía anteriores a la guerra, cuando, como escribe en los primeros versos del libro, "con un dolor de playas de amor en un costado, [...] entré al cielo abierto del Museo del Prado" (691, 3, 1-4). Según el propio Alberti, el libro se conformó a partir del caos del mundo e intentó oponerse a él; era un homenaje a la paz. ${ }^{6}$

La poesía es así para Alberti la manifestación de un deseo de orden; es la construcción y reconstrucción de la memoria: una experiencia salvadora y, de cierta forma, la única opción. Su libro A la pintura es un buen ejemplo de la esperanza ecfrástica, de la creencia en la capacidad del lenguaje de hacernos ver, de acercarnos a aquello a lo cual se refiere. También es un ejemplo de la nostalgia utópica que muchos exiliados vivieron y escribieron. Por eso escribe un poema que supone análogo a un cuadro que veía en su país, que pretende hacernos ver el Bodegón de Zurbarán, en todo lo que le es visible e invisible.

Finalicemos volviendo al poema y a la analogía con el pintor que ya se había presentado en la tercera estrofa en la sesgada referencia a la escritura con "el pergamino que alumbra la madera" y, en la sexta estrofa, con el juego entre el lienzo, la tela, la aguja y la línea. La arpillera de la tercera estrofa y los pliegues del ropaje de la quinta, que recuerdan muchos de los cuadros de Zurbarán, parecen ser en realidad el motivo de la representación, como en el poema son las palabras. Así, recordamos que la naturaleza muerta y sus paradojas acaban siempre subrayando el arte mismo ("La nube es un soporte, es una baja / plataforma celeste suspendida, / donde un arcángel albañil trabaja en mostrar que hay otra vida. / Mas lo que muestra es siempre un andamiaje

\footnotetext{
6 "for it is not just recreation, but also a creation, a deft and lovely shaping of reality. Alberti has said that he hoped (it) might contribute, in some small way, to the reemergence of beauty, harmony and order in his ravaged world ... The collection... was fashioned, Alberti has said, 'after all the chaos' and set up in opposition to it; this is why he first offered it as an homage to peace" (Tipton: xix).
} 
/ para enganchar en pliegues el ropaje"). Y todo, a partir de los objetos más simples.

Los más comunes y que siempre pasamos por alto.

\section{Obras citadas}

Alberti, Rafael. 1972. Poesía (1924-1967). Madrid: Aguilar.

BoYM, Svetlana. 1996. "Estrangement as a Lifestyle; Shklovsky and Brodsky". Poetics

Today, vol. 17, núm. 4. Creativity and Exile; European/American Perspectives II (Winter, 1996). Pp. 511-530.

BRYSOn, Norman. 1990. Looking at the Overlooked. Four Essays on Still Life Painting. Cambridge, Massachusetts: Harvard University Press.

Colie, Rosalie L. 1966. Paradoxa Epidemica. The Renaissance Tradition of Paradox. Princeton, N. J.: Princeton University Press.

DAVENPORT, Guy. 1998. Objects on a Table. Harmonious Disarray in Art and Literature. Washington, D. C.: Counterpoint.

FERNÁNDEZ ROMERO, Ricardo. 2005. "La autobiografía y la escritura del deseo". Cuadernos Hispanoamericanos, 656, feb. Pp. 33-40.

GONZÁLEZ, Bernardo Antonio. 1990. "Ekphrasis and Autobiography: The Case of Rafael Alberti”. Anales de la Literatura Española Contemporánea, 15: 1-3. Pp.29-49.

Guerrero Ruiz, Pedro. 1999. "Recuerdos del Prado: A la pintura de Rafael Alberti”. Revista Canadiense de Estudios Hispánicos, 24:1 (Fall). Pp. 171-190.

HefFERnAn, James W. 1993. Museum of Words. The Poetics of Ekphrasis from Homer to Ashbery. Chicago / Londres: The University of Chicago Press.

HERRERA ESPINOSA, Rafael. 2006. "A la pintura: un libro de homenajes". Juan Ramón, Alberti: dos poetas líricos. Kassel: Reichenberg. Pp.311-321

LaJER-Burcharth, Ewa. 2005. "The Object as Subject". The Lure of the Object. Stephen MelviLle, ed. Williamstown, Mass.: Sterling and Francine Clark Institute. Pp.157-177.

Onieva Ramírez, Francisco. 2006. "La maestría de Alberti en A la pintura. Claves fundamentales". Juan Ramón, Alberti: dos poetas líricos. Kassel: Reichenberg. Pp. 290-310.

PIMENTEL, Luz Aurora. 2003. "Ecfrasis y lecturas iconotextuales”. Poligrafías. Revista de Literatura Comparada, núm. 4. México: UNAM, Facultad de Filosofía y Letras. Pp. 205-215.

STOICHITA, Victor. 1993. La invención del cuadro. Arte, artífices y artificios en los orígenes de la pintura europea. Barcelona: Serbal.

TiPTON, Carolyn. 1997. Introducción y notas a To Painting: Poems by Rafael Alberti. Ill.: Northwestern University Press.

YACOBI, Tamar. 1998. "The Ekphrastic Model: Forms and Functions". Pictures into Words. Theoretical and Descriptive Aproaches to Ekphrasis. Ámsterdam: VU University Press. 